\title{
Smart passive damper control for greater building earthquake resilience in sustainable cities
}

\author{
$\operatorname{AUTHOR}(\mathrm{S}):$ \\ Takewaki, I.; Fujita, K.; Yamamoto, K.; Takabatake, \\ $\mathrm{H}$.
}

\section{CITATION:}

Takewaki, I. ... [et al]. Smart passive damper control for greater building earthquake resilience in sustainable cities. Sustainable Cities and Society 2011, 1(1): 3-15

\section{ISSUE DATE:}

2011-02

URL:

http://hdl.handle.net/2433/157310

\section{RIGHT:}

(c) 2010 Elsevier B.V.; This is not the published version. Please cite only the published version.; この論文は出版社版でありません。引用の際に は出版社版をご確認ご利用ください。 


\title{
Smart Passive Damper Control for Greater Building Earthquake Resilience in Sustainable Cities
}

\author{
I.Takewaki $^{1}{ }^{1} *$, K.Fujita ${ }^{2)}$, K.Yamamoto ${ }^{2)}$ and H.Takabatake ${ }^{3)}$ \\ 1) Department of Architecture and Architectural Engineering \\ ${ }^{2)}$ Department of Urban and Environmental Engineering \\ Graduate School of Engineering, Kyoto University \\ Kyotodaigaku-Katsura, Nishikyo-ku, Kyoto 615-8540, Japan \\ 3) Department of Architecture, Kanazawa Institute of Technology \\ 7-1 Ohgigaoka, Nonoichi, Ishikawa 921-8501, Japan
}

\begin{abstract}
Passive dampers are used recently in many mid and high-rise buildings. This trend is accelerated by the increased demand and desire for safer, more reliable and more comfortable buildings under uncertain external loading and environment. Viscous, visco-elastic, hysteretic and friction dampers are representatives of passive dampers. Such passive dampers also play a key role in the implementation of structural rehabilitation which is essential for the realization and promotion of sustainable buildings. The technique of structural health monitoring is inevitable for the reliable and effective installation of passive dampers during the structural rehabilitation or retrofit.

The design earthquake ground motions change from time to time when a new class of ground motions (e.g. long-period ground motions due to surface waves) is observed or a new type of damage appears during severe earthquakes. The concept of critical excitation is useful in responding to this change together with the usage of passive dampers from the viewpoint of sustainable buildings and cities.

In this paper, a historical review is made on the development of smart or optimal building structural control with passive dampers and some possibilities of structural rehabilitation by use of passive dampers are discussed.
\end{abstract}

Keywords: Sustainable buildings, Rehabilitation of buildings, Passive building control, Structural control, Passive dampers, Earthquake engineering, Seismic retrofit

*Corresponding author, E-mail: takewaki@archi.kyoto-u.ac.jp 


\section{INTRODUCTION}

The structural rehabilitation or retrofit of buildings has been conducted for a long time all over the world and the structural control using passive dampers plays a key role in the implementation of the structural rehabilitation or retrofit which is essential for the realization of sustainable buildings and cities.

The structural control has a long and successful history in mechanical and aerospace engineering. This is because these fields usually deal with controllable external loading and environment with little uncertainty. However, in the field of civil engineering, it has a different background (Housner et al. 1994, Housner et al. 1997, Soong and Dargush 1997, Kobori et al. 1998, Srinivasan and McFarland 2000, Casciati 2002, Christopoulos and Filiatrault 2006, Johnson and Smyth 2006, de Silva 2007). Building and civil structures are often subjected to severe earthquake ground motions, wind disturbances and other external loading with large uncertainties. It is therefore inevitable to take into account of these uncertainties in the theory of structural control and its application to actual structures. There are five important areas impacted by structural control (Soong 1998), i.e. (a) systems approach, (b) deepening effect, (c) broadening effect, (d) experimental research and (e) creative engineering. Among these five areas, the broadening effect includes the smart use of passive dampers in building structures.

In the early stage of development in passive structural control, the installation itself of supplemental dampers in ordinary buildings was the central objective and many successful applications have been made. It seems natural that, after extensive developments of various damper systems, another objective and target were aimed at accelerating the development of smart and effective installation of supplemental passive dampers. This trend corresponds well to the promotion of new design methods for building structures from the viewpoint of sustainability and efficient use of materials.

Although the motivation was inspired and directed to smart and effective installation of supplemental passive dampers, research on optimal passive damper placement has still been very limited. The following studies may be relevant to this subject. Gurgoze and Muller (1992) presented a numerical method for finding the optimal placement and the optimal damping coefficient for a single viscous damper in a given linear multi-degree-of-freedom system. Zhang and Soong (1992) proposed a seismic design method to find the optimal location of viscous dampers for a building with specified story stiffnesses. While their method is based upon an intuitive criterion that an additional damper should be placed sequentially on the story with the maximum interstory drift, it is pioneering. Hahn and Sathiavageeswaran (1992) performed several parametric investigations on the effects of damper distribution on the earthquake response of shear buildings, and showed that, for a building with uniform story stiffnesses, dampers should be added to the lower half floors of the building. Tsuji and Nakamura (1996) proposed an algorithm to find both the optimal story stiffness and damper distributions for a shear building model subjected to a set of spectrum-compatible earthquakes.

Rather recently Takewaki (1997, 1999a, b) opened another door of smart passive damper placement with the help of the concepts of inverse problem approaches and optimal criteria-based design approaches. He solved a problem of optimal passive damper placement by deriving the optimality criteria and then by developing an incremental inverse problem approach. For many years, this research played a role as a pioneering work in this area and many researchers referred to this article and compared the results by their methods with the 
result by Takewaki (1997). Subsequently, Takewaki et al. (1998, 1999) and Takewaki (2000) introduced a new approach based on the concept of optimal sensitivity. The optimal quantity of passive dampers is obtained automatically together with the optimal placement through this new method. The detailed explanation of this approach is made in Takewaki $(2009,2010)$.

After these researches, many related works have been developed (Singh and Moreschi 2001, Garcia 2001, Silvestri et al. 2003, Uetani et al. 2003, Trombetti and Silvestri 2004, Lavan and Levy 2006, Silvestri and Trombetti 2007, Aydin et al. 2007, Cimellaro 2007, Fujita et al. 2010a, b, Yamamoto et al. 2010). Although most of the research are based on gradient-based approaches, a GA-based approach is also investigated (Lavan and Dargush 2009). Most of them investigated new optimal design methods of supplemental dampers and proposed effective and useful methods.

There are several textbooks dealing with the design of passive dampers. Connor and Klink (1996) introduced a concept of 'motion-based design' and provided versatile explanation on various passive and active control systems, i.e. viscoelastic, viscous and tuned-mass dampers, base-isolation systems and active control systems. Soong and Dargush (1997) explain the fundamental mechanical aspects of passive dampers and present many practical examples of application to realistic buildings. Hanson and Soong (2001) begin with basic concepts of passive dampers and present a few examples of application. Christopoulos and Filiatrault (2006) deal with passive energy dissipation systems and base-isolated buildings. They treat several different systems of supplemental dampers, i.e. metallic and friction dampers, viscous and visco-elastic dampers, self-centering characteristic dampers, tuned-mass dampers, etc. They also explain the energy principle and performance-based design principle. de Silva (2007) collects many useful chapters for passive damper systems and gives an up-to-date review. Takewaki (2009) provided several gradient-based approaches.

The design earthquake ground motions change from time to time when a new class of ground motions (e.g. long-period ground motions due to surface waves) is observed or a new type of damage appears during severe earthquakes. The concept of critical excitation is useful in responding to this change and should be used as a next-generation paradigm for unpredictable design ground motions together with the usage of passive dampers from the viewpoint of sustainable buildings and cities.

\section{REALIZATION OF SUSTAINABLE BUILDINGS FROM THE VIEWPOINT OF STRUCTURAL ENGINEERING}

The structural rehabilitation is essential for the cost-effective realization of sustainable buildings and many useful methods have been proposed. Passive dampers enable the structural rehabilitation inevitable for the realization and promotion of sustainable buildings. The most advantageous aspects of using passive dampers are to be able to use various types of passive dampers, i.e. viscous, viscoelastic, hysteretic and friction dampers, depending on the type of buildings to be rehabilitated. Each type of damper has its features and simultaneous usage of different dampers helps the compensation of demerits.

Table 1 shows the pros and cons of various passive dampers. The most important aspect is to prevent from introducing excessive additional forces in the original frames to be rehabilitated. The phase delay and relief mechanism in viscous (oil) dampers and the series-type allocation of multiple passive dampers are regarded as key mechanisms. 
Table 1 Pros and cons of passive dampers

\begin{tabular}{|c|c|c|}
\hline & Pros & Cons \\
\hline Viscous damper & $\begin{array}{c}\text { Do not introduce excessive } \\
\text { additional force into structural } \\
\text { frames (Phase delay and relief } \\
\text { mechanism) }\end{array}$ & $\begin{array}{c}\text { Can not respond to impulsive } \\
\text { loading }\end{array}$ \\
\hline Visco-elastic damper & Cost effective & $\begin{array}{c}\text { Introduce excessive additional } \\
\text { force into structural frames; } \\
\text { Temperature, frequency, } \\
\text { amplitude-dependence }\end{array}$ \\
\hline $\begin{array}{c}\text { Hysteretic damper (shear, } \\
\text { buckling-restrained brace) }\end{array}$ & Cost effective & $\begin{array}{c}\text { Introduce excessive additional } \\
\text { force into structural frames } \\
\text { Feliability of control of } \\
\text { slippage force }\end{array}$ \\
\hline
\end{tabular}

In the structural rehabilitation, the structural health monitoring plays a significant role so as to maintain the effectiveness and reliability of rehabilitation. Many useful system identification methods have been proposed so far. Interested readers should read (Boller et al. 2009). There are two types of system identification techniques, i.e. modal parameter system identification and physical parameter system identification (Takewaki and Nakamura 2000, 2005).

The design earthquake ground motions change from time to time when a new class of ground motions (e.g. long-period ground motions due to surface waves) is observed or a new type of damage appears during severe earthquakes. Passive dampers are useful to respond to this change regardless of whether the object building is a newly constructed one or one to be rehabilitated. The concept of critical excitation is also useful to respond to this change together with the usage of passive dampers from the viewpoint of sustainable buildings and cities. The critical excitation method plays an important role in the point that it can incorporate inexperienced, undesirable inputs in the design stage (see Fig.1).

There are various buildings in a city. Each building has its natural period and original structural properties. When an earthquake occurs, ground motions of various properties are induced in the city. The combination of the building natural period with the predominant period of the induced ground motion may lead to disastrous phenomena in the city. Many past earthquake ground motions exhibited such phenomena. To the authors' knowledge, the concept of 'critical excitation' and the structural design based upon this concept can become one of such new paradigms.

It may be natural to assume that earthquake has a bound on its magnitude. In other words, the earthquake energy radiated from the fault has a bound. The problem is to find the most unfavorable ground motion for a building or a group of buildings (see Fig.1, Takewaki 2007, 2008a).

A displacement spectrum or acceleration spectrum of ground motions has been proposed at the rock surface depending on the seismic moment, distance from the fault, etc. (Fig.2). Such spectrum may have uncertainties. One possibility or approach is to specify the acceleration or velocity power and allow the variability of the spectrum.

The problem of ground motion variability is very important and tough. Code-specified 
design ground motions are usually constructed by taking into account of the knowledge from the past observation and the probabilistic insights. However, uncertainties in the occurrence of earthquakes (or ground motions), the fault rupture mechanisms, the wave propagation mechanisms, the ground properties, etc. cause much difficulty in defining reasonable design ground motions especially for important buildings in which severe damage or collapse has to be avoided absolutely.

A significance of critical excitation is supported by its broad perspective. There are two classes of buildings in a city (see Fig.3). One is the important buildings which play an important role during disastrous earthquakes. The other one is ordinary buildings. The former one should not have damage during earthquake and the latter one may be damaged partially especially for critical excitation larger than code-specified design earthquakes. The concept of critical excitation may enable structural designers to make ordinary buildings more seismic-resistant.

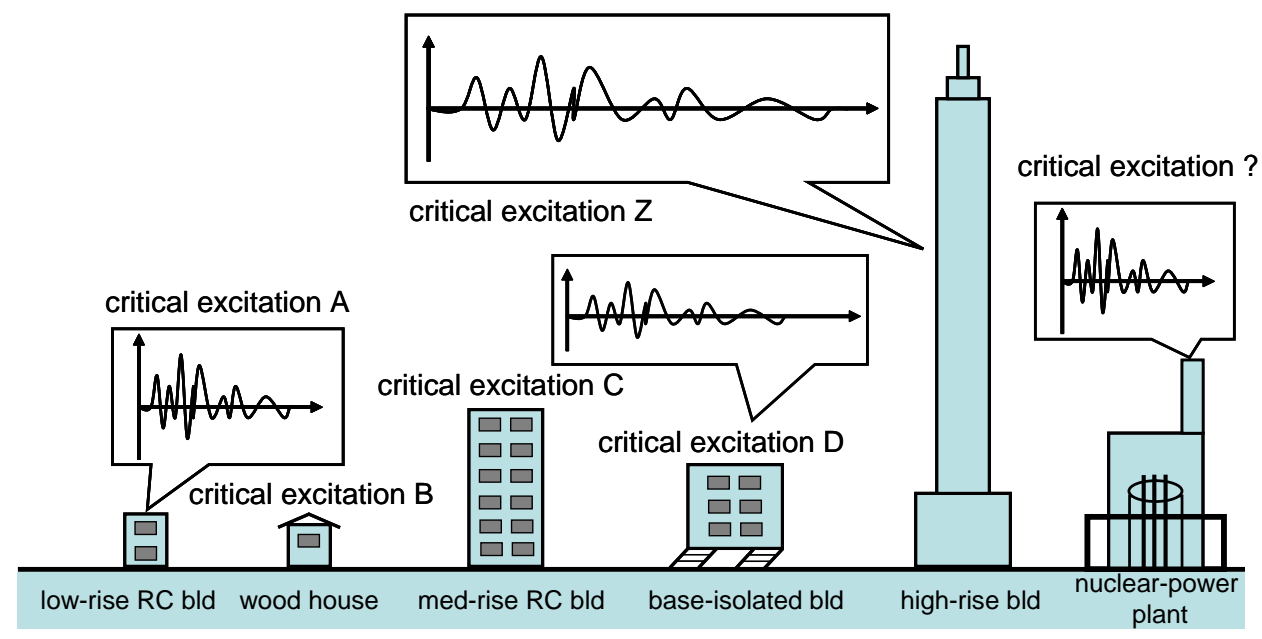

Fig.1 Various critical excitations for different types of buildings

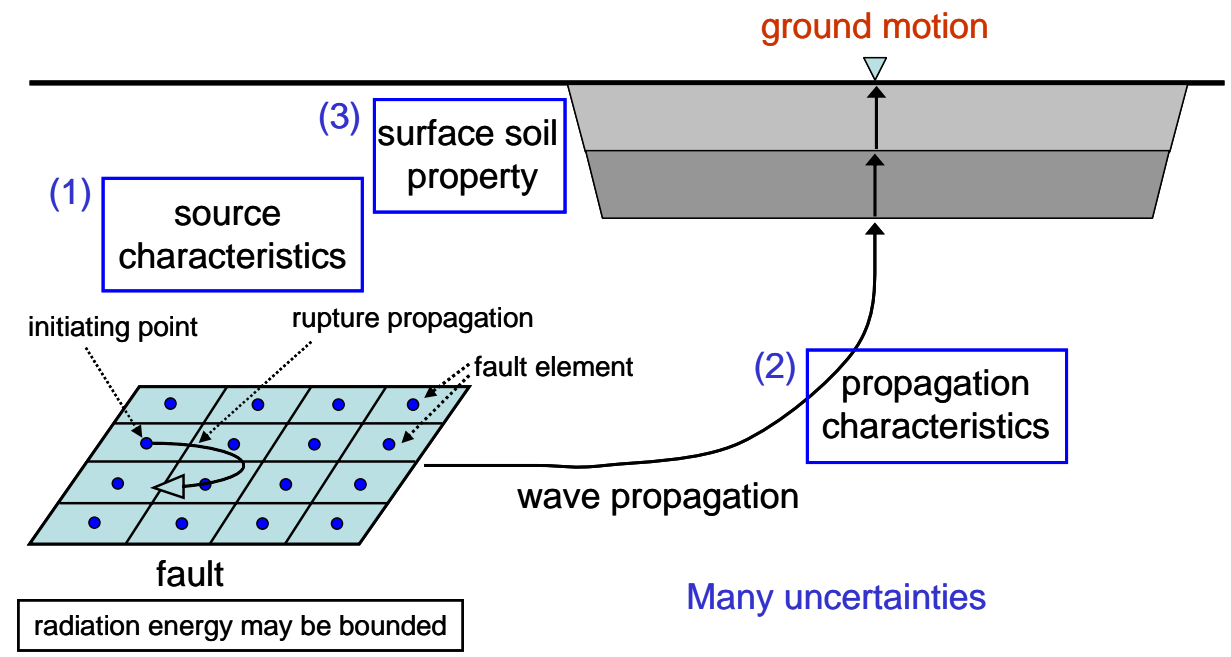

Fig.2 Earthquake ground motion depending on fault rupture mechanism, wave propagation and surface ground amplification, etc. 

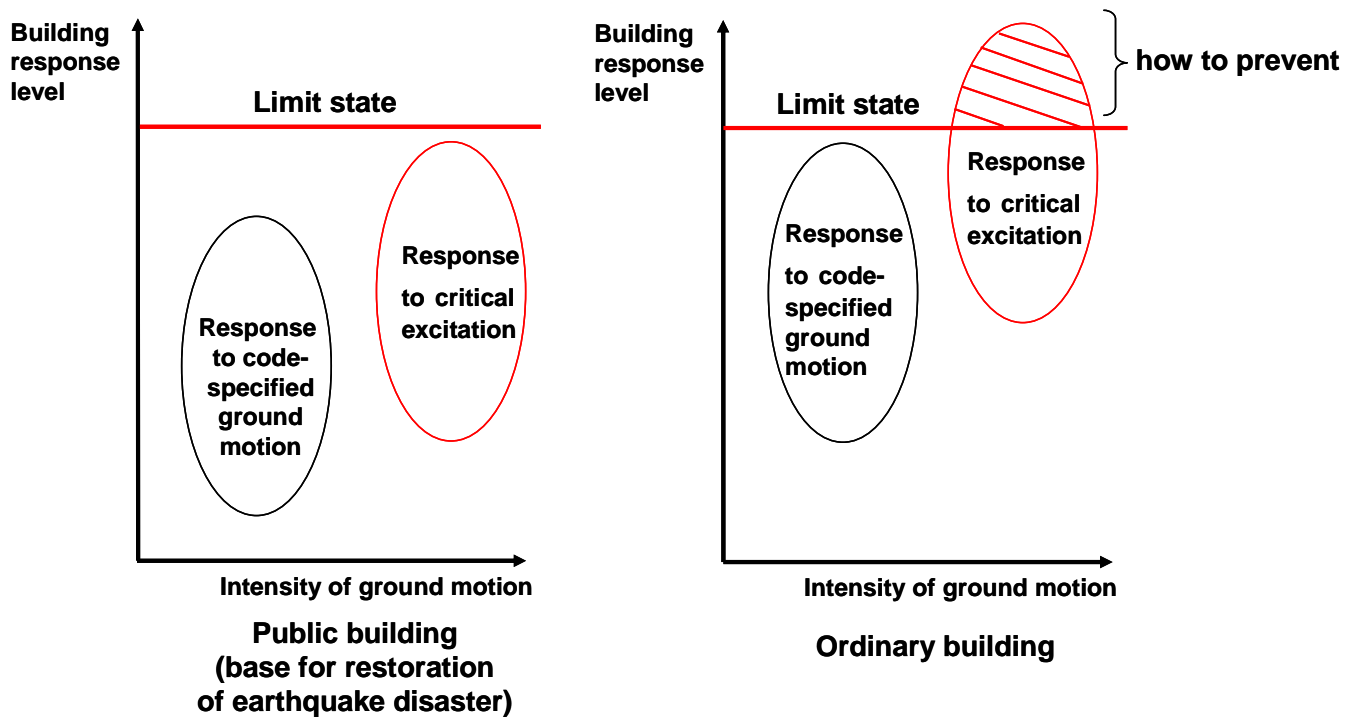

Fig.3 Relation of critical excitation with code-specified ground motion in public building and ordinary building

\section{FUNDAMENTALS OF PASSIVE-DAMPER INSTALLATION}

Three principal types of passive control systems installed in building structures are (i) story-installation type supplemental passive dampers (viscous damper, visco-elastic damper, hysteretic damper), (ii) tuned-mass dampers (TMD) and (iii) base-isolation systems as shown in Fig.4.

Story-installation type supplemental passive dampers are principally treated in this section. As for tuned-mass dampers and base-isolated buildings (see Fig.4), refer to Takewaki (2009). In order to present fundamental basics for mechanical modeling of these story-installation type supplemental passive dampers, viscous and visco-elastic dampers are taken as examples.
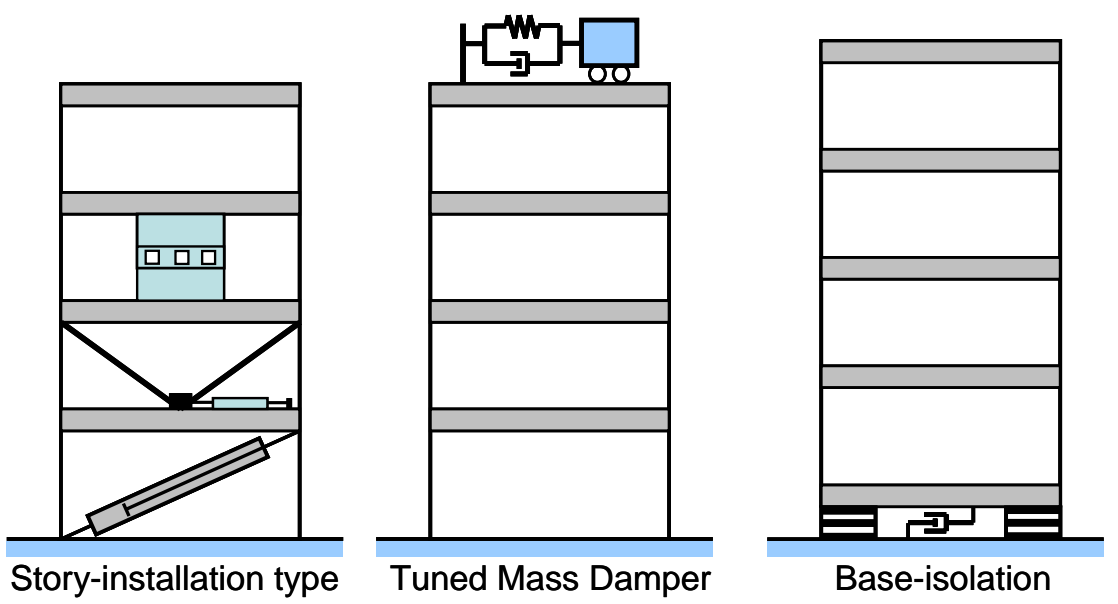

Fig.4 Three principal installation types of passive dampers 

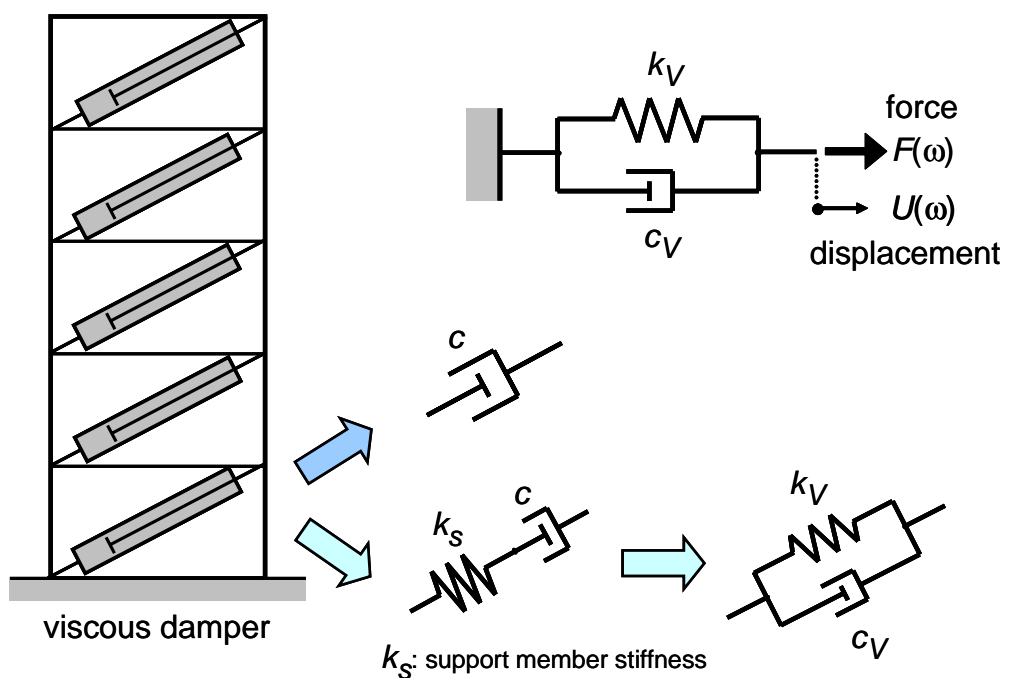

Fig.5 Passive damper system including a viscous damper and its modeling into dashpot model and Maxwell model

\section{[Viscous dampers]}

The passive damper system, as shown in Fig.5, including a viscous damper can be modeled into two models. One is the dashpot and the other is the dashpot supported by a spring. The latter model is a Maxwell-type model. Let $c$ denote the damping coefficient of the dashpot and $k_{S}$ denote the stiffness of the supporting spring. This supporting spring represents the stiffness of the viscous damper device itself, e.g. an oil damper, or the stiffness of the surrounding supporting system.

As for the Maxwell-type model, let us assume that the force-displacement relation in the frequency domain can be described by

$$
F(\omega)=\left(K_{R}+\mathrm{i} K_{I}\right) U(\omega)=\left(k_{V}+\mathrm{i} \omega c_{V}\right) U(\omega) .
$$

In Eq.(1), $k_{V}$ and $c_{V}$ denote the stiffness of the spring and the damping coefficient of the dashpot of the pseudo Kelvin-Voigt model transformed from the Maxwell-type model.

The complex stiffness in Eq.(1) may be derived as follows from the formulation of the series model of the dashpot and the supporting spring.

$$
K_{R}+\mathrm{i} K_{I}=\frac{1}{\frac{1}{\mathrm{i} \omega c}+\frac{1}{k_{S}}}
$$

This is the standard treatment of series models. After some manipulation, the real and imaginary parts of the complex stiffness in Eq.(2) may be expressed by

$$
K_{R}(\omega)=k_{V}(\omega)=\frac{k_{S} c^{2} \omega^{2}}{k_{S}^{2}+c^{2} \omega^{2}}
$$




$$
K_{I}(\omega)=\omega c_{V}(\omega)=\frac{k_{S}^{2} c \omega}{k_{S}^{2}+c^{2} \omega^{2}}
$$

It can be understood from Eqs.(3) and (4) that $k_{V}$ and $c_{V}$ are functions of the excitation frequency $\omega$. This property may be used in the representation of frequency-dependent characteristic via series models.

\section{[Visco-elastic dampers]}

The passive damper system, as shown in Fig.6, including a visco-elastic damper can be modeled into two models. One is the Kelvin-Voigt model and the other is the Kelvin-Voigt model with a support. Let $k$ denote the stiffness of the visco-elastic damper itself and $c$ denote the damping coefficient of the visco-elastic damper itself. On the other hand, $k_{S}$ denotes the stiffness of the supporting spring. This supporting spring represents the stiffness of the visco-elastic damper device itself, e.g. steel attachment of the visco-elastic material, or the stiffness of the surrounding supporting system. It is well known that $k$ and $c$ of most of visco-elastic materials depend on frequency, vibration amplitude and temperature, etc. Therefore the treatment of visco-elastic damper devices is more difficult than viscous dampers in general.

As for the Kelvin-Voigt model with a support, assume that the force-displacement relation in the frequency domain can be described by

$$
F(\omega)=\left(K_{R}+\mathrm{i} K_{I}\right) U(\omega)=\left(k_{E}+\mathrm{i} \omega c_{E}\right) U(\omega) \text {. }
$$

In Eq.(5), $k_{E}$ and $c_{E}$ denote the stiffness of the spring and the damping coefficient of the dashpot of the pseudo Kelvin-Voigt model transformed from the Kelvin-Voigt model with a support.

The complex stiffness of this pseudo Kelvin-Voigt model may be derived as follows from the normal formulation of the series model of the Kelvin-Voigt model and the supporting spring.

$$
K_{R}+\mathrm{i} K_{I}=\frac{1}{\frac{1}{k+\mathrm{i} \omega c}+\frac{1}{k_{S}}}
$$

After some manipulation, the real and imaginary parts of the complex stiffness in Eq.(6) may be expressed by

$$
\begin{aligned}
& K_{R}(\omega)=k_{E}(\omega)=\frac{k_{S}\left(k^{2}+k k_{S}+c^{2} \omega^{2}\right)}{\left(k+k_{S}\right)^{2}+c^{2} \omega^{2}} \\
& K_{I}(\omega)=\omega c_{E}(\omega)=\frac{\omega k_{S}{ }^{2} c}{\left(k+k_{S}\right)^{2}+c^{2} \omega^{2}} .
\end{aligned}
$$


It can be understood from Eqs.(7) and (8) that $k_{E}$ and $c_{E}$ are functions of the excitation frequency as in Eqs.(3) and (4).

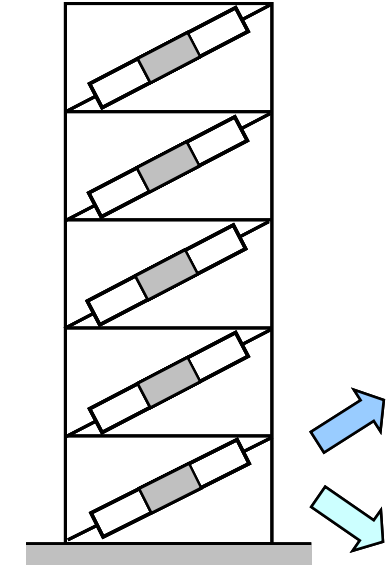

visco-elastic damper
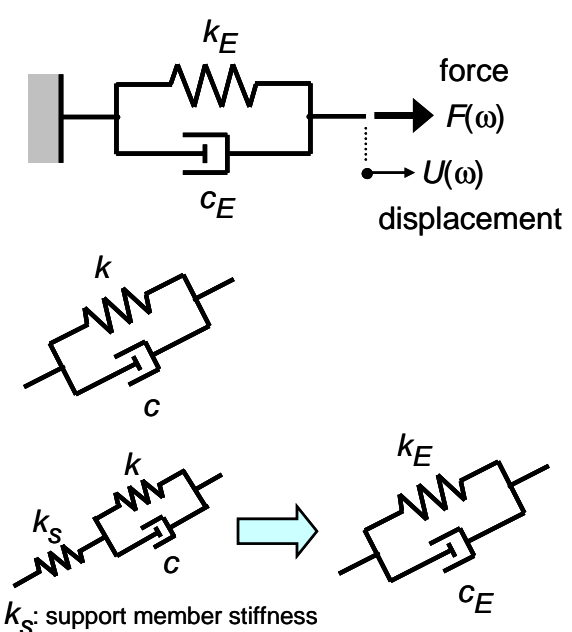

Fig.6 Passive damper system including a visco-elastic damper and its modeling into Kelvin-Voigt model and Kelvin-Voigt model with support

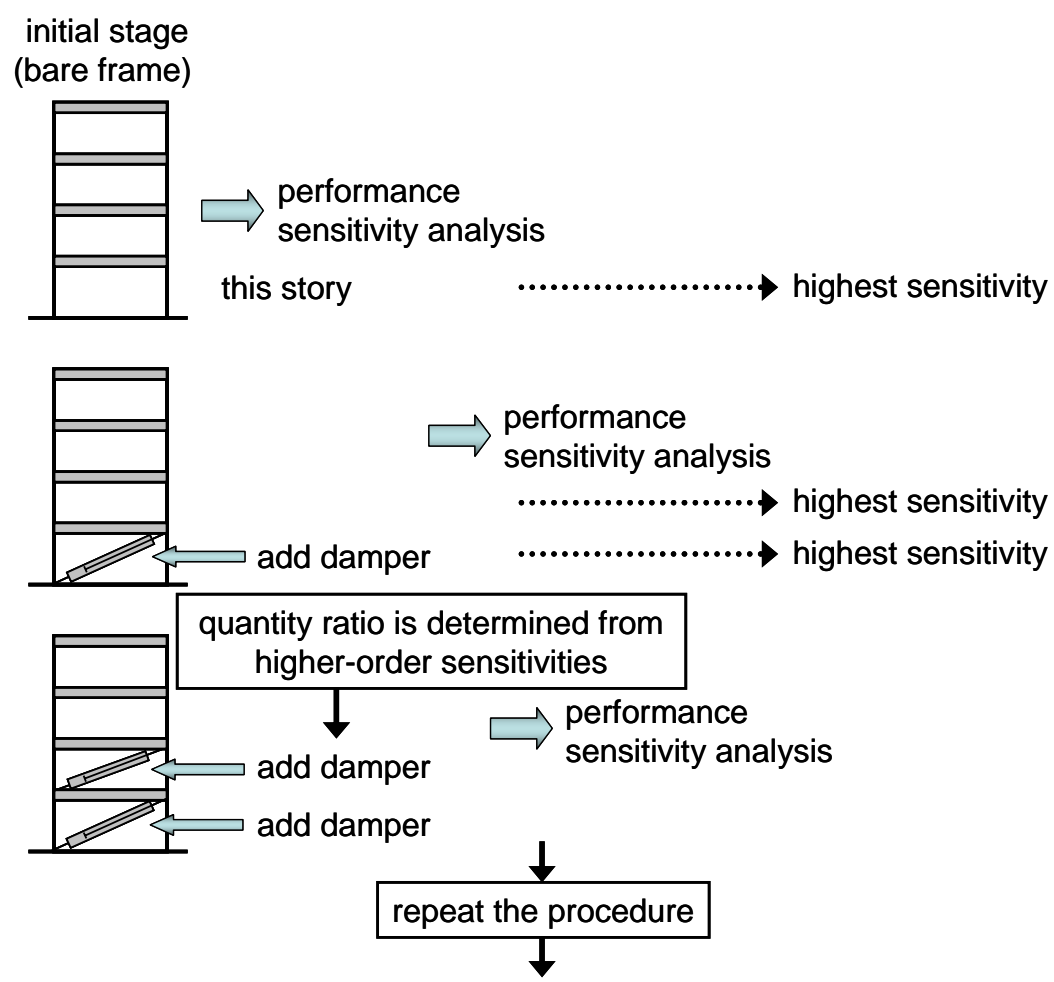

Fig.7 A representative schematic diagram of optimization procedures 
Fig.7 shows a representative schematic diagram for the gradient-based optimization procedures. The optimization procedures are based on the optimality criteria and related performance sensitivities. The damper placement criteria are derived from these optimality criteria and performance sensitivities. In Fig.7, the initial design is a bare frame without supplemental dampers. Sensitivity analysis of the objective function with respect to a design variable (damping coefficient of supplemental damper) is performed first for this bare frame and the highest performance sensitivity is found. Then the additional supplemental damper is added to this story. This implies that the supplemental damper with the highest performance sensitivity can decrease the performance most effectively and the damping coefficient should be increased in this supplemental damper. Again sensitivity analysis is performed for the frame with a supplemental damper and the highest performance sensitivity is found sequentially. If the multiple stories show the highest performance sensitivity, then the damping coefficients of the corresponding supplemental dampers are increased. Again sensitivity analysis is performed for the frame with supplemental dampers and repeat the procedure explained above until the required total quantity of supplemental dampers is reached.

\section{THEORETICAL BASIS OF EFFECTIVENESS OF SUPPLEMENTAL DAMPERS}

If the earthquake input energy criterion holds even approximately regardless of the existence of supplemental dampers and the supplemental passive dampers can absorb the earthquake input energy as greatly as possible, the input energy to the frame can be reduced drastically (see Fig.8). Although main frames are usually designed so as to remain elastic in the case of using passive energy dissipation systems, inelastic dynamic responses of building structures with viscous or hysteretic dampers are also discussed from the viewpoint of effectiveness of viscous and hysteretic dampers.
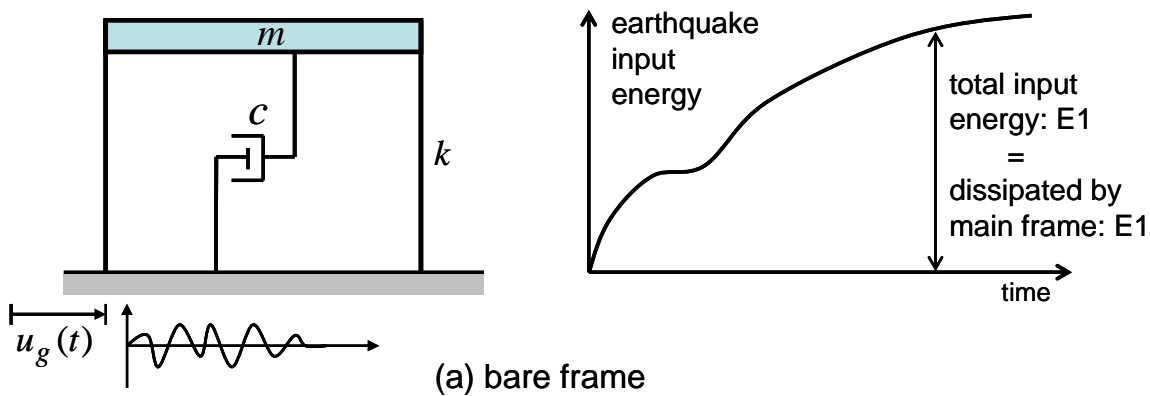

(a) bare frame
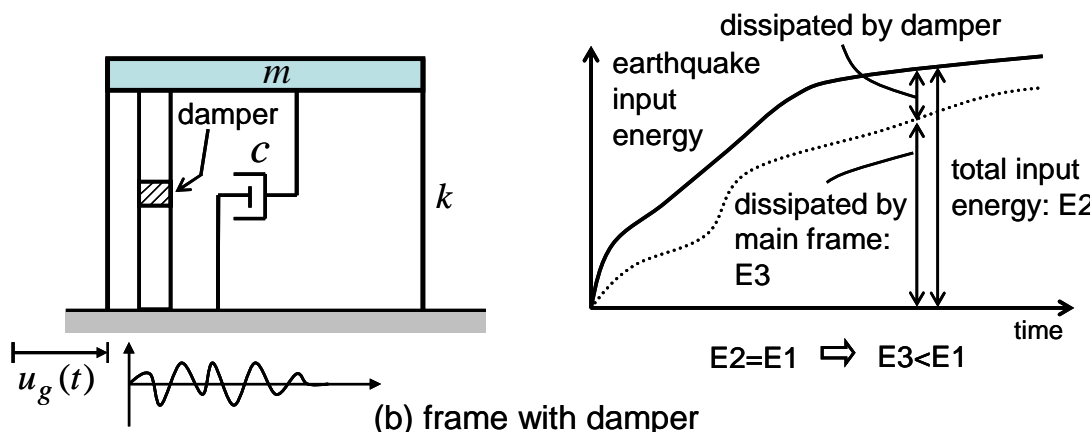

(b) frame with damper

Fig.8 Theoretical basis of effectiveness of supplemental dampers 


\section{CONSTANT EARTHQUAKE INPUT ENERGY CRITERION TO MDOF MODEL IN FREQUENCY DOMAIN}

Consider a proportionally damped multi-degree-of-freedom (MDOF) structure with the mass matrix $[M]$. Let $\{x\}$ denote the horizontal nodal displacements of masses relative to the ground and let $\{1\}$ denote the influence coefficient vector. The input energy to this MDOF structure may be described as

$$
E_{I}=-\int_{-\infty}^{\infty}\{\dot{x}\}^{T}[M]\{1\} \ddot{u}_{g} \mathrm{~d} t
$$

Application of the inverse Fourier transformation $\{\dot{x}\}^{T}=\int_{-\infty}^{\infty}\{\dot{X}\}^{T} e^{\mathrm{i} \omega t} \mathrm{~d} \omega / 2 \pi$ to Eq.(9a) leads to

$$
E_{I}=-\int_{-\infty}^{\infty}\left[\frac{1}{2 \pi} \int_{-\infty}^{\infty}\{\dot{X}\}^{T} e^{\mathrm{i} \omega t} \mathrm{~d} \omega\right][M]\{1\} \ddot{u}_{g} \mathrm{~d} t
$$

Let $\left\{H_{V}\left(\omega ; \Omega_{i}, h_{i}\right)\right\}, \Omega_{i}, h_{i}$ and $[\Phi]$ denote the velocity transfer function, the $i$-th undamped natural circular frequency, the $i$-th damping ratio and the modal matrix. Substitution of the relations $\{\dot{X}(\omega)\}=[\Phi]\left\{H_{V}\left(\omega ; \Omega_{i}, h_{i}\right)\right\} \ddot{U}_{g}(\omega)$ and $\ddot{U}_{g}(-\omega)=\int_{-\infty}^{\infty} \ddot{u}_{g}(t) e^{\mathrm{i} \omega t} \mathrm{~d} t \quad$ into Eq.(9b) provides

$$
E_{I}=\int_{0}^{\infty}\left|\ddot{U}_{g}(\omega)\right|^{2} F_{M P}(\omega) \mathrm{d} \omega
$$

In Eq.(10), $F_{M P}(\omega)$ may be defined by

$$
F_{M P}(\omega)=-\frac{1}{\pi}\left\{\operatorname{Re}\left[H_{V}\left(\omega ; \Omega_{i}, h_{i}\right)\right]\right\}^{T}[\Phi]^{T}[M]\{1\}
$$

If $\left|\ddot{U}_{g}(\omega)\right|$ is constant $(=\bar{A}$ ) with respect to frequency, the input energy may be expressed as

$$
E_{I}=\bar{A}^{2} \int_{0}^{\infty} F_{M P}(\omega) \mathrm{d} \omega
$$

Substitution of Eq.(11) into Eq.(12) leads to

$$
E_{I}=-\frac{\bar{A}^{2}}{\pi}\left\{\int_{0}^{\infty} \operatorname{Re}\left[H_{V}\left(\omega ; \Omega_{i}, h_{i}\right)\right] \mathrm{d} \omega\right\}^{T}[\Phi]^{T}[M]\{1\}
$$

With the help of the residue theorem in each mode, the input energy to the proportionally damped MDOF structure may result in 


$$
E_{I}=\frac{1}{2} \bar{A}^{2}\{1\}^{T}[\Phi]^{T}[M]\{1\}=\frac{1}{2} \bar{A}^{2} \sum_{j=1}^{N} m_{j}
$$

$N$ denotes the number of masses and $m_{j}$ is the mass corresponding to the $j$-th horizontal nodal displacement. Eq.(14) implies that, if the Fourier amplitude is constant with respect to frequency, the input energy to the proportionally damped MDOF structure depends only on the total mass of the model.

The relation of Eq.(14) can also be derived by the idea in the time domain because the initial velocity $-\bar{A}$ is given simultaneously at all the masses by an ideal input with a constant Fourier amplitude spectrum (see Fig.9, Takewaki and Fujita 2009).

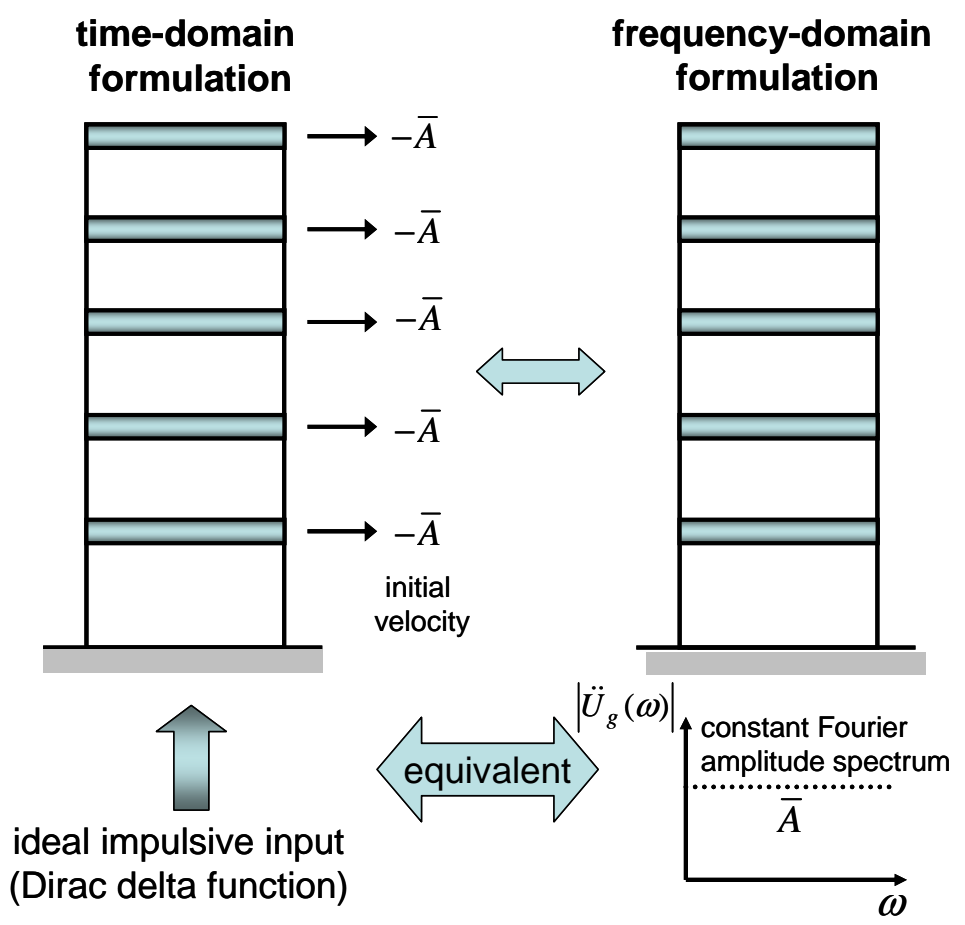

Fig.9 Correspondence of time and frequency-domain dual formulations

\section{STRUCTURAL BUILDING MODELS FOR DAMPER DESIGN}

The problems of optimal viscous damper placement have been treated in various types of structures or structural systems. Some of them will be shown here.

A shear building model as shown in Fig.10 is a simplest model and is being used as a benchmark model for demonstration of damper effectiveness. Takewaki (1997) presented a simple gradient-based and optimality criteria-based approach to the smart installation problem of dampers in this model. Fig.11 shows a schematic diagram of the relation of the gradient vector of the objective function (performance) $V=\hat{\delta}_{1}(\mathbf{c})+\hat{\delta}_{2}(\mathbf{c})$ ( $\hat{\delta}_{i}(\mathbf{c})$ : amplitude of interstory-drift transfer function at the undamped fundamental natural frequency) with the constraint $c_{1}+c_{2}=\bar{W}$ on total damper quantity. 


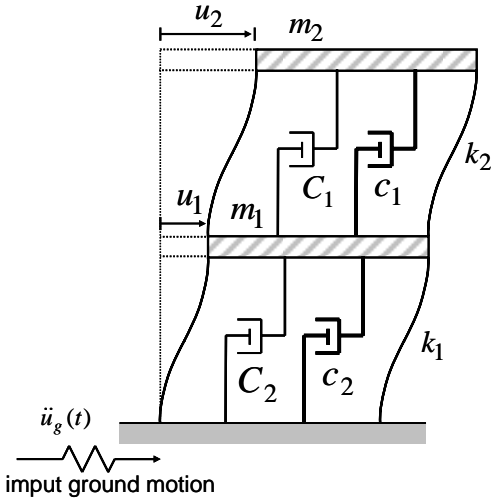

Fig.10 Shear building model

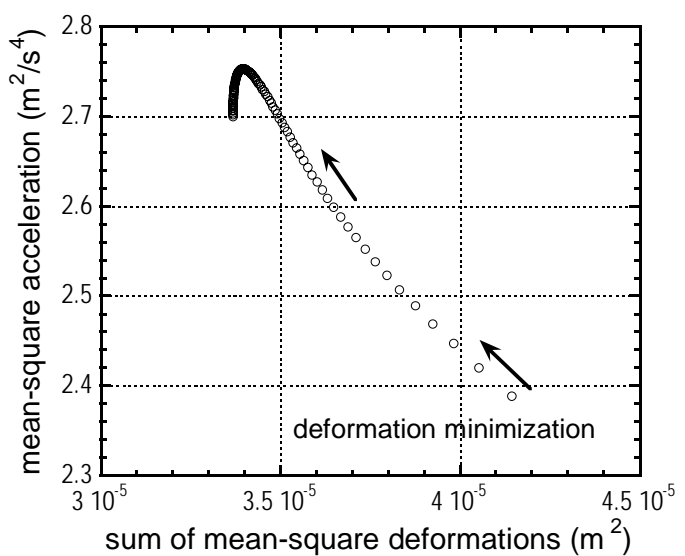

(a)

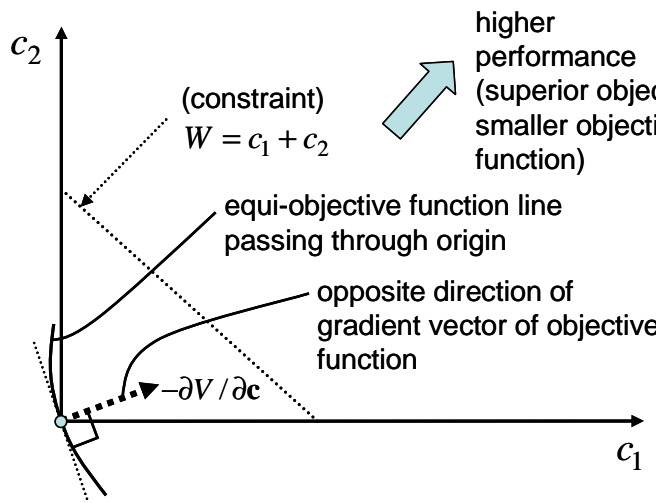

Fig.11 Schematic diagram of the relation of the gradient vector of the objective function with the constraint on damper quantity

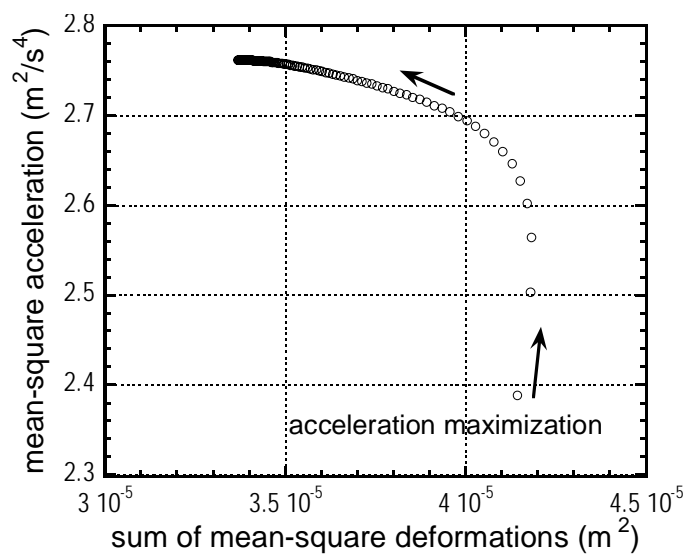

(b)

Fig.12 Multi-criteria plot with respect to sum of mean-square deformations and mean-square acceleration; (a) Deformation minimization, (b) Acceleration maximization

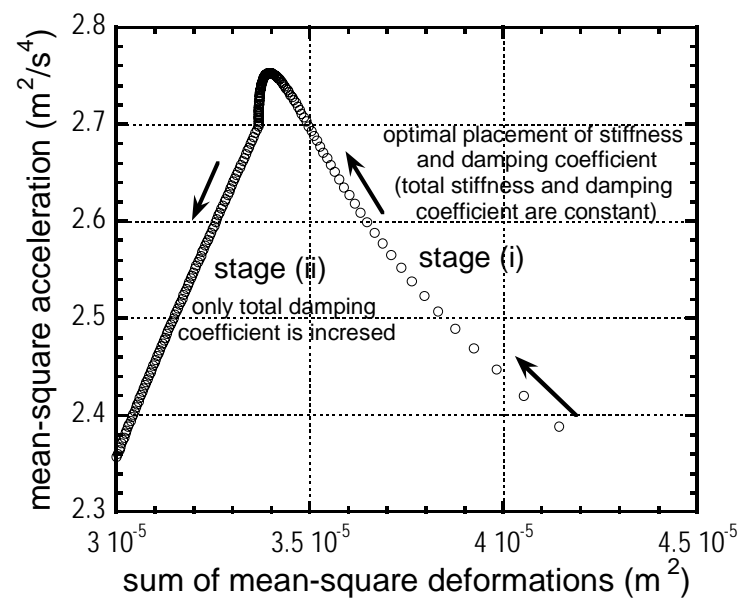

Fig.13 Multi-criteria plot by using two-step procedure for deformation-acceleration simultaneous control 


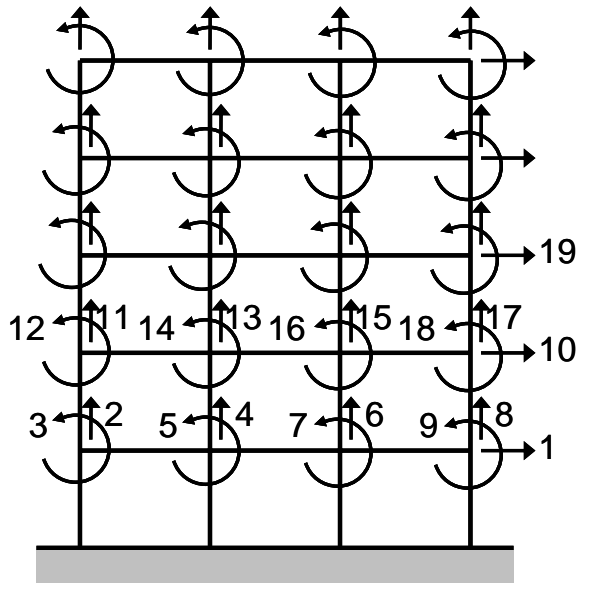

(a)

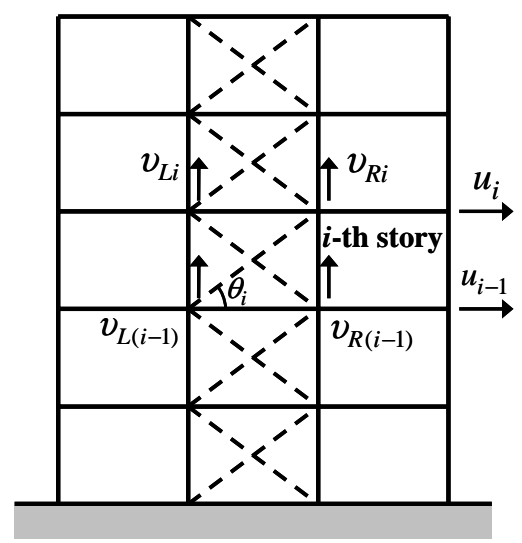

(b)

Fig.14 Two-dimensional planar building frame

Takewaki (1999a) introduced a new concept of displacement-acceleration simultaneous control via stiffness-damping collaboration. Fig.12 illustrates the multi-criteria plot with respect to sum of mean-square deformations and mean-square acceleration: (a) Plot for deformation minimization, (b) Plot for acceleration maximization. For more flexible control, Fig.13 shows the multi-criteria plot by using the two-step procedure for deformation-acceleration simultaneous control.

A shear-flexural building model is an extended model of the shear building model and can take into account the overall flexural behavior of high-rise buildings. The number of degrees-of-freedom of the shear-flexural building model is two times the number of stories. A planar frame model as shown in Fig.14 is the most detailed two-dimensional model which can consider the member response of framed buildings. Takewaki (2000) and Takewaki et al. (1999) proposed a new gradient-based approach to the problem of optimal damper placement for smart design. Fig.15(a) presents the fundamental algorithm and Fig.15(b) shows the augmented algorithm which is needed for avoid of negative damper installation.

A 3-D shear building model as shown in Fig.16 is another extension of the shear building model which can deal with the torsional response of 3-D buildings. Other extensions of the shear building model can be explained by the building-ground model as shown in Figs.17 and 18, building-pile-soil model and building-TMD model as shown in Fig.17, etc. These models can take into account the interaction of the building with surrounding mediums or devices. 


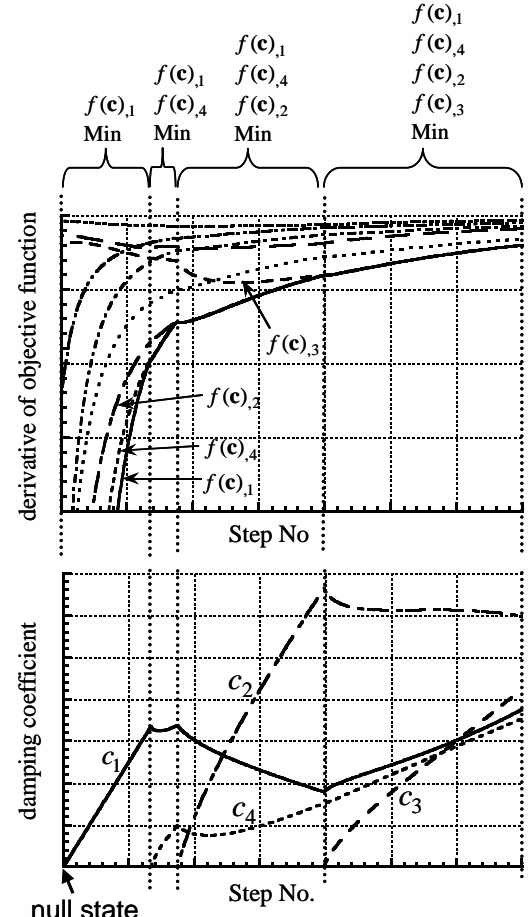

(a)

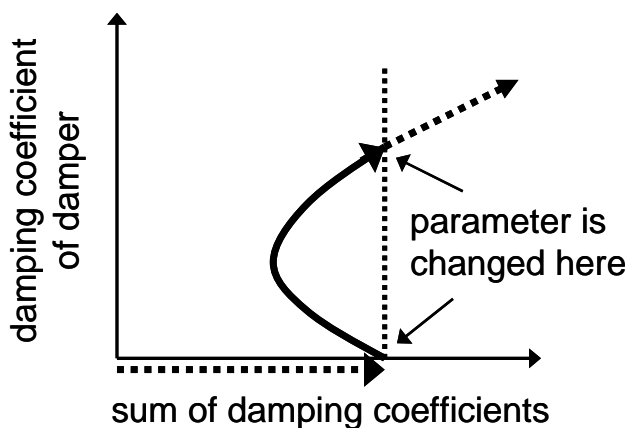

design parameter

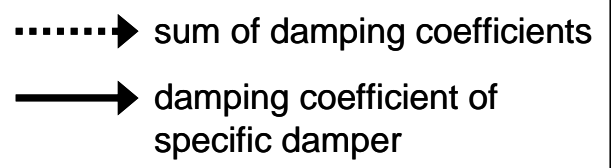

(b)

Fig.15 Algorithm for optimal damper placement ; (a) Fundamental algorithm, (b) Augmented algorithm

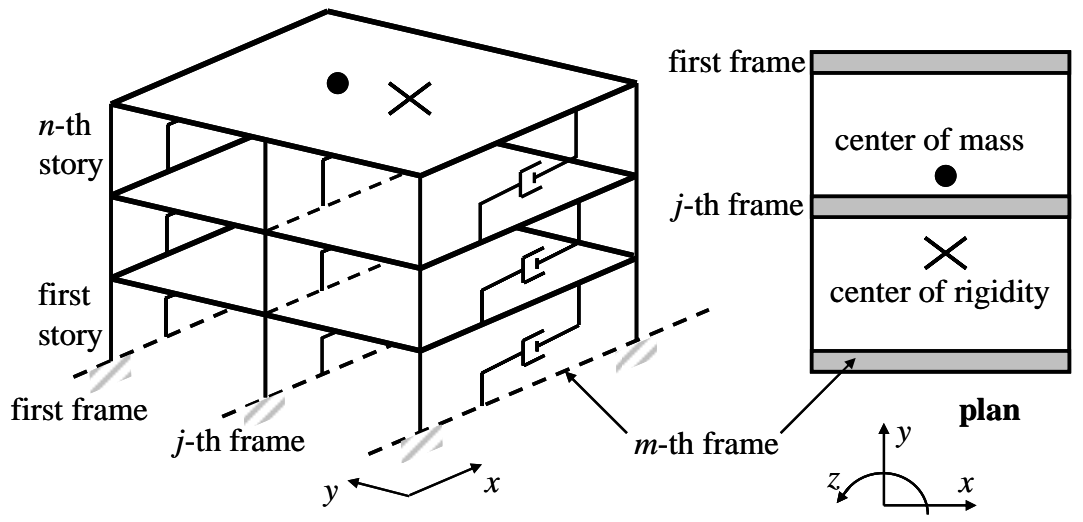

Fig.16 Three-dimensional shear building model 


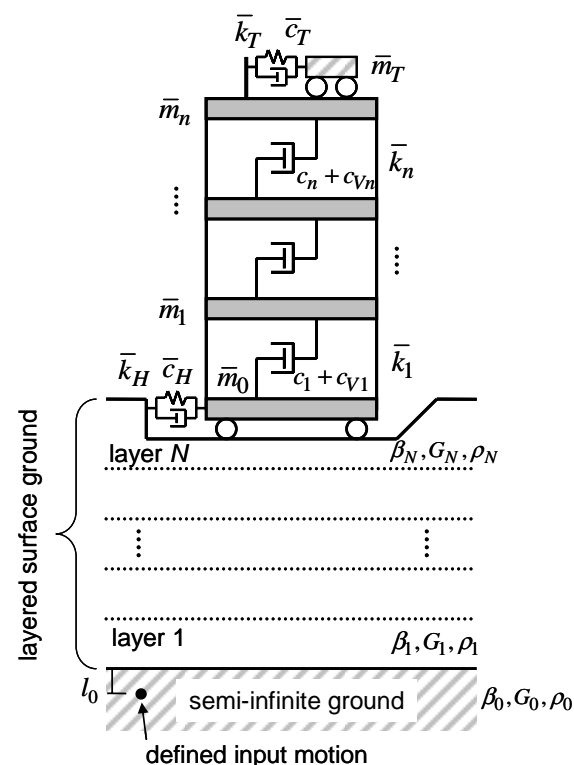

(a) Physical parameter

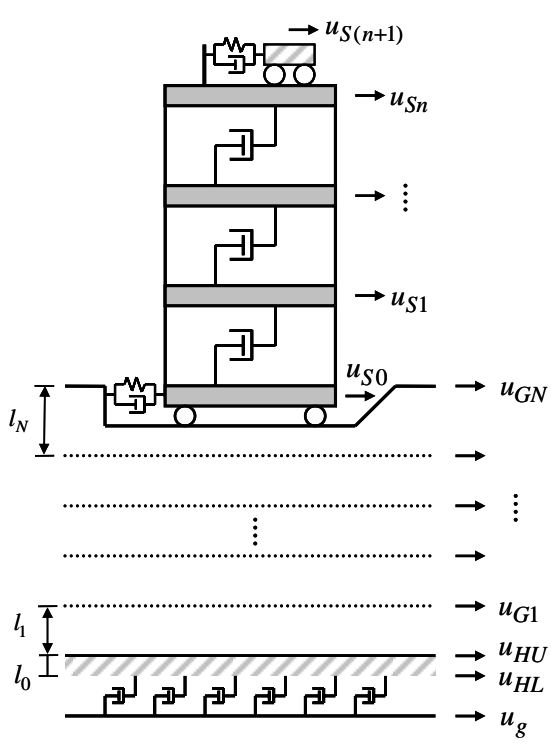

(b) Modeling in terms of viscous boundary and displacement

Fig.17 Shear building-ground system with a tuned mass damper
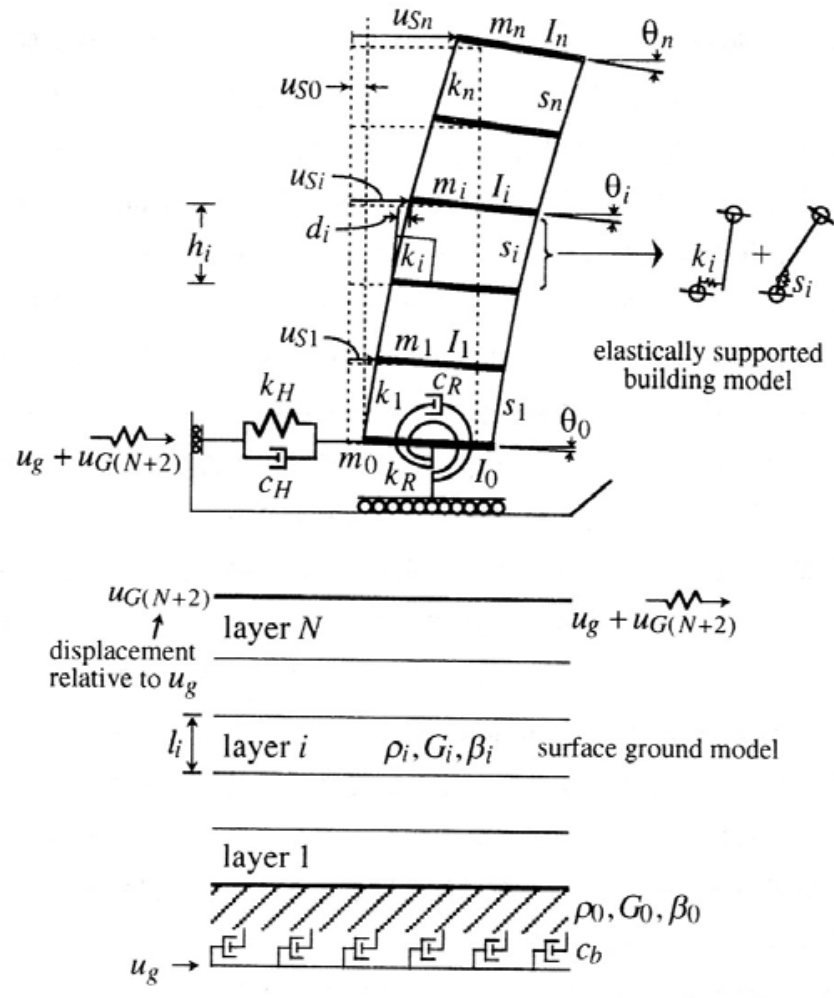

Fig.18 Shear-flexural building model supported by ground 

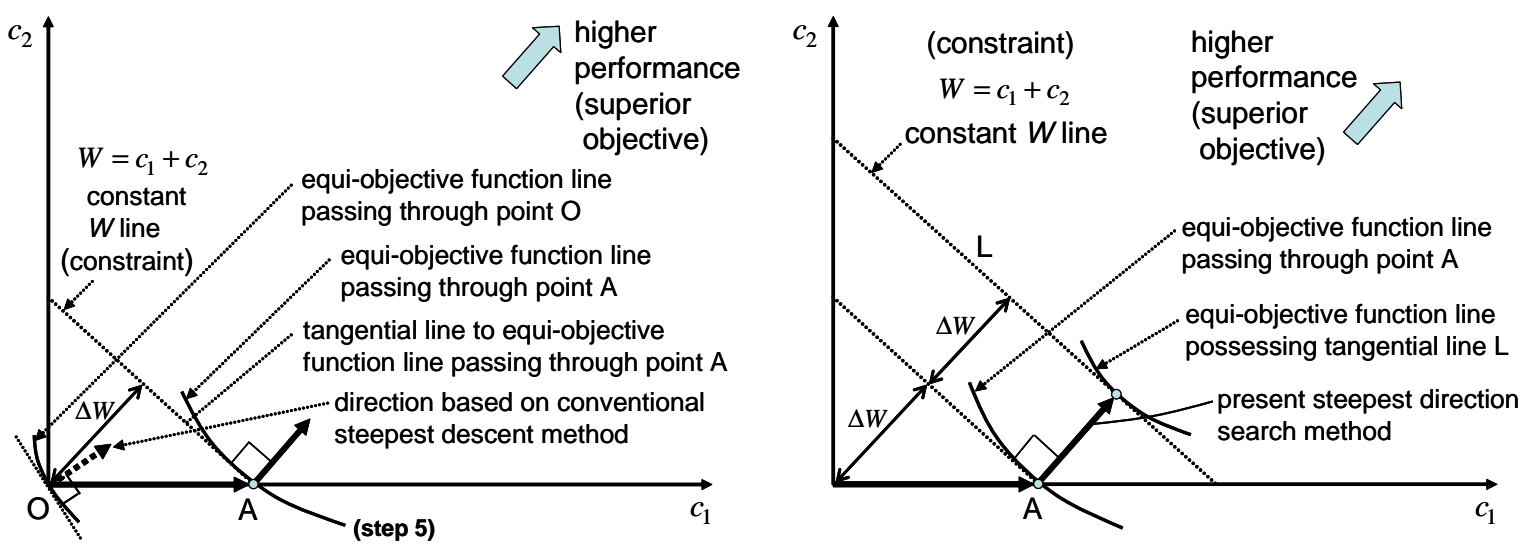

Fig.19 Comparison of the proposed steepest direction search method with the conventional steepest descent method

Fig.19 explains the comparison of the proposed steepest direction search method (Takewaki 2000, Takewaki et al. 1999, Fujita et al. 2010a, b) with the conventional steepest descent method. It should be noted that the ratio of the stiffness of members or elements supporting the dampers to the story stiffness of the structural frame is a key parameter in the effective use of passive dampers (Takewaki and Yoshitomi 1998, Fujita et al. 2010a).

\section{OBJECTIVE FUNCTIONS FOR OPTIMAL DAMPER DESIGN}

The examples of the objective function used in the problems of optimal damper placement are as follows:

The sum of the interstory-drift transfer function amplitudes at the fundamental natural frequency through stories is a fundamental flexibility measure of the shear building model (Takewaki 1997). This quantity is a measure of the building itself and does not depend on the input of earthquake ground motions. Other examples of the objective function are a probabilistic response quantity, an earthquake response quantity, the maximum value of interstory-drift transfer function (Fujita et al. 2010b) and an $H^{\infty}$ norm (Yamamoto et al. 2010).

The explained gradient-based approach is based on the Lagrange multiplier method for optimization. It is useful to investigate the global optimality of the solution. Fig.20 shows the comparison of the variation of the objective function, i.e., the sum of the mean-squares of the interstory drifts, for various structural models with randomly placed VD under a constant total damper capacity. The stiffnesses of damper supporting members are treated here. From Fig.20, the optimal damper placement derived by the Lagrange multiplier method decreases the objective function most effectively and gives the global optimal solution. This figure verifies the validity of the proposed optimization methodology. 


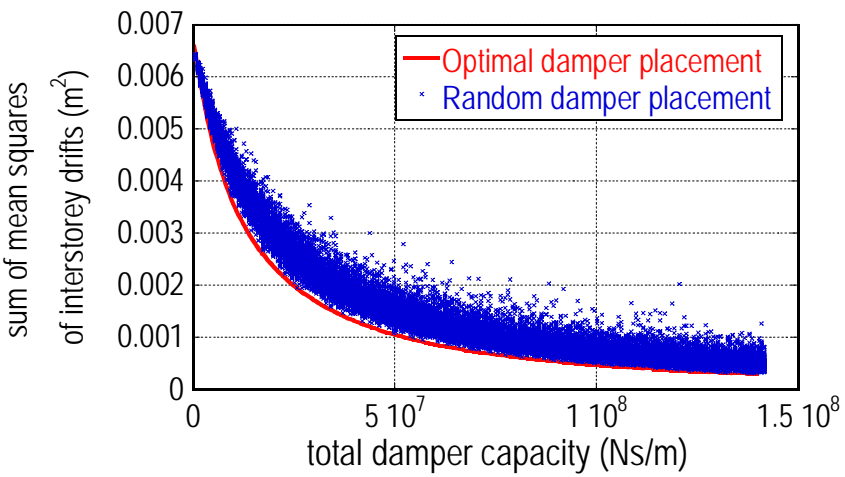

Fig.20 Comparison of objective functions for random damper placement with that for the optimal placement

\section{OPTIMAL DAMPER DESIGN UNDER UNCERTAIN CONDITIONS}

Sources of uncertainties in structural engineering usually come from input earthquake ground motions and parameter variability in structures (Takewaki and Ben-Haim 2005, Takewaki 2007, 2008a, b). It is well accepted in earthquake prone countries that the former uncertainties govern the principal design stage. However, the latter uncertainties are also important in the stage of design decision. Fig.21 shows the design-dependent critical excitation and effective damper placement for critical excitation. It is very important in this situation to introduce a framework to describe the uncertainty. Takewaki and Ben-Haim (2005, 2008) developed a unified theory for taking into account of both uncertainties stated above by introducing an info-gap robustness function. Fig.22 shows the info-gap robustness function $\hat{\alpha}$ with respect to design requirement $f_{\mathrm{C}}$.

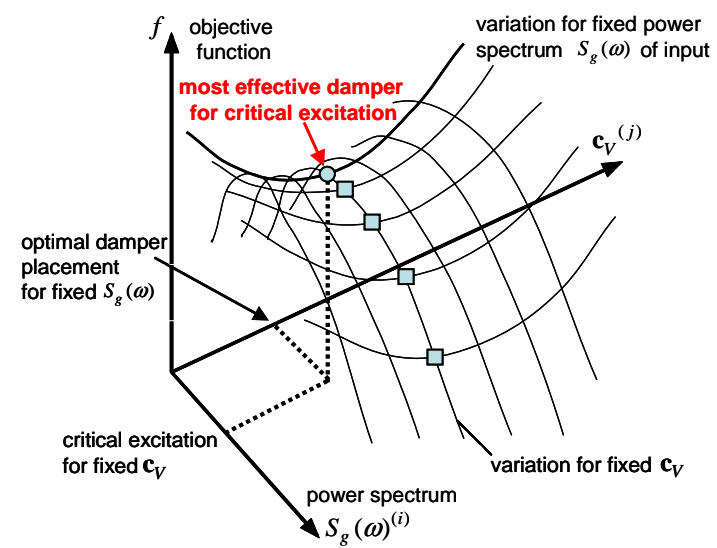

Fig.21 Design-dependent critical excitation and effective damper placement for critical excitation

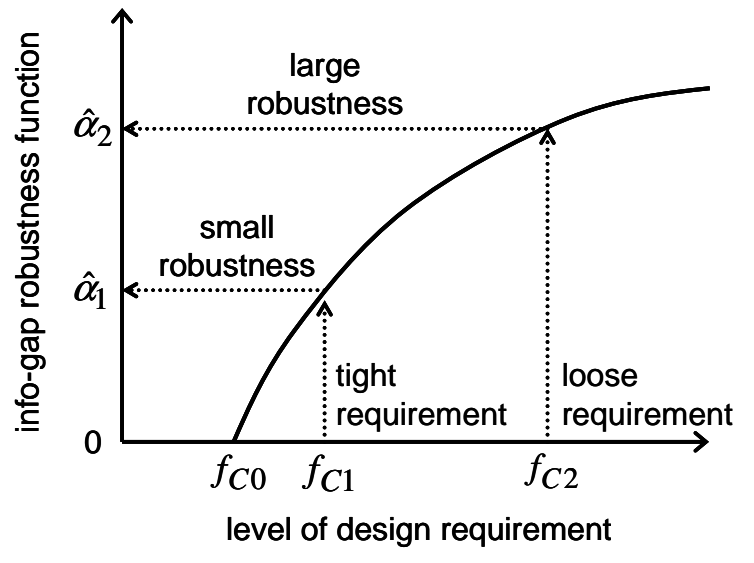

Fig.22 Info-gap robustness function $\hat{\alpha}$ with respect to level of design requirement $f_{\mathrm{C}}$ 


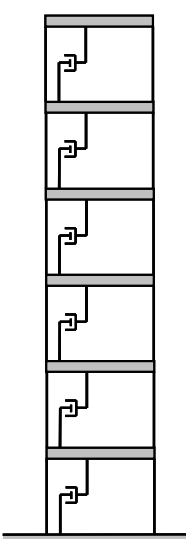

(a)

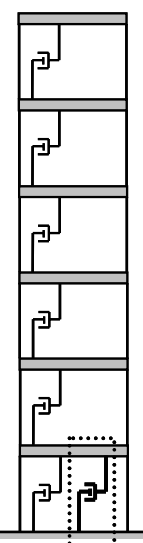

(b)

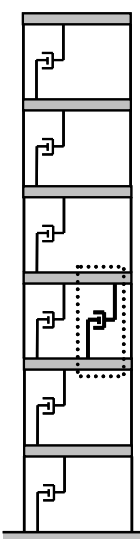

(c)

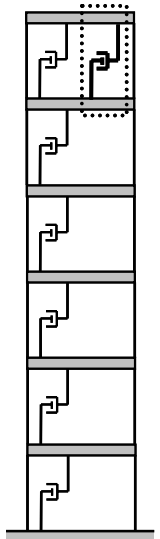

(d)

Fig.23 Six-story shear building model; (a) bare frame, (b) frame with added damper in the first story, (c) frame with added damper in the third story, (d) frame with added damper in the sixth story
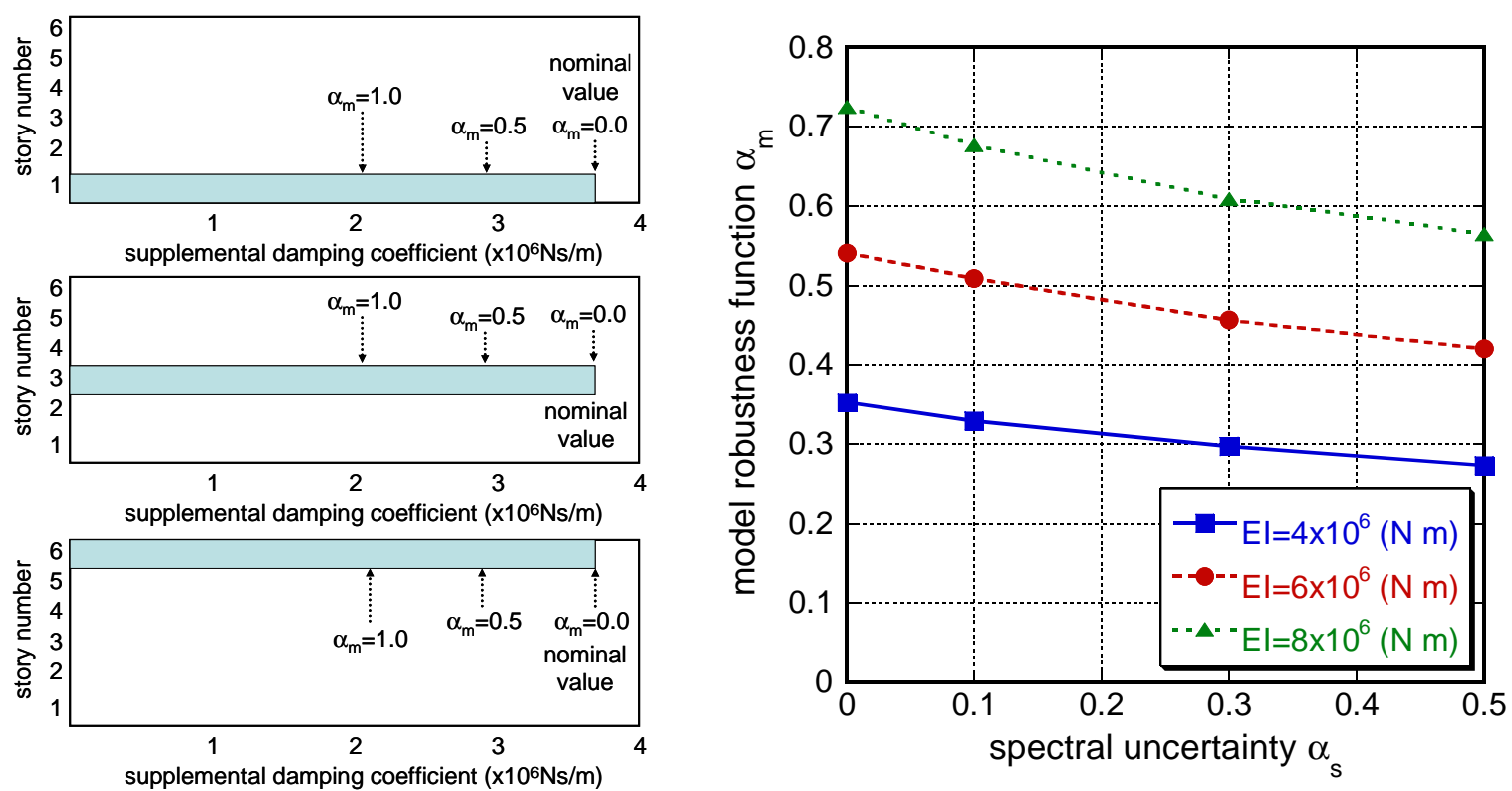

Fig.24 Supplemental viscous damping coefficient; first-story allocation, third-story allocation, sixth-story allocation from the top

Fig.25 Plot of the info-gap robustness function $\hat{\alpha}_{\mathrm{m}}$ with respect to the level of the load spectral uncertainty $\alpha_{\mathrm{s}}$ for various requirements of earthquake input energies $E_{I}=4.0 \times 10^{6}, 6.0 \times 10^{6}, 8.0 \times 10^{6}(\mathrm{~N} \mathrm{~m})$ (first-story damping model)

Consider a six-story shear building model; (a) bare frame, (b) frame with added damper in the first story, (c) frame with added damper in the third story, (d) frame with added damper in the sixth story as shown in Fig.23. The supplemental damper has an uncertainty in its damping coefficient. The description of the uncertainty in terms of the parameter $\alpha_{\mathrm{m}}$ is illustrated in Fig.24. The plot of the info-gap robustness function $\hat{\alpha}_{\mathrm{m}}$ with respect to the level of the load spectral uncertainty $\alpha_{\mathrm{s}}$ for various requirements of earthquake input energies $E_{I}=4.0 \times 10^{6}$, 
$6.0 \times 10^{6}, 8.0 \times 10^{6}(\mathrm{Nm})$ (first-story damping model) is shown in Fig.25. It can be observed that the info-gap robustness function $\hat{\alpha}_{\mathrm{m}}$ and the level of the load spectral uncertainty $\alpha_{\mathrm{s}}$ introduce a new trade-off relationship.

Another approach to the smart passive damper design under uncertainties of ground motions is the method for the minimum $H^{\infty}$ norm. Yamamoto et al. (2010) developed an optimal placement method of passive viscous dampers in a shear building model. The $H^{\infty}$ norm of the transfer function matrix of interstory drifts has been adopted as the objective function. Since it represents the magnitude of vibration transfer (Fig.26), one can attenuate the gain of the frequency response by minimizing this norm. The sequential quadratic programming (SQP) method has been employed for optimization.

To demonstrate the practical applicability of the present design method, a five-story damped shear building model has been considered. The floor masses and story stiffnesses are prescribed as $m_{i}=5.12 \times 10^{5}[\mathrm{~kg}]$ and $k_{i}=6.02 \times 10^{8}[\mathrm{~N} / \mathrm{m}](i=1, \cdots, 5)$, respectively. The structural damping ratio of the main frame is assumed to be 0.02 (stiffness-proportional damping).

Fig.27 provides the distribution of damping coefficients obtained by this optimization method. Fig.28(a)-(d) present the maximum interstory drifts of the models with various damper placements (1st story alone, uniform placement, optimal placement) under recorded ground motions. In addition, Fig.28(e) shows the maximum interstory drifts of the model without passive dampers under four recorded ground motions. These values are obtained by time history response analysis. As seen in these figures, the proposed method can achieve a remarkable improvement for various earthquake ground motions.

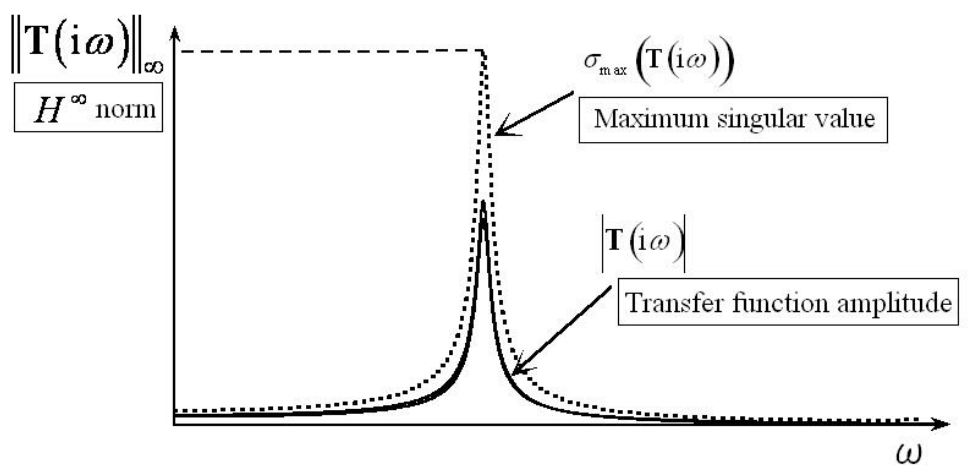

Fig.26 $H^{\infty}$ norm of the transfer function matrix of interstory drifts

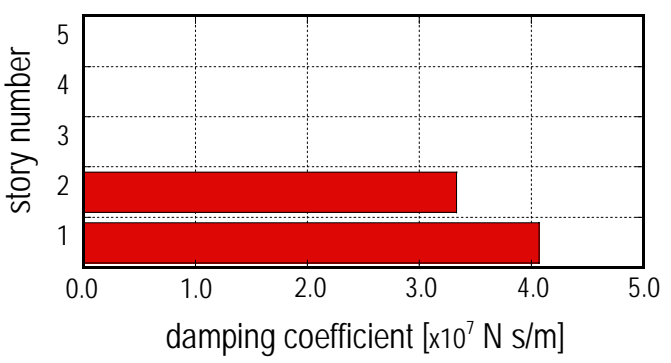

Fig.27 Optimal viscous damping coefficient distribution for minimum $H^{\infty}$ norm of the transfer function matrix of interstory drifts 
(a)

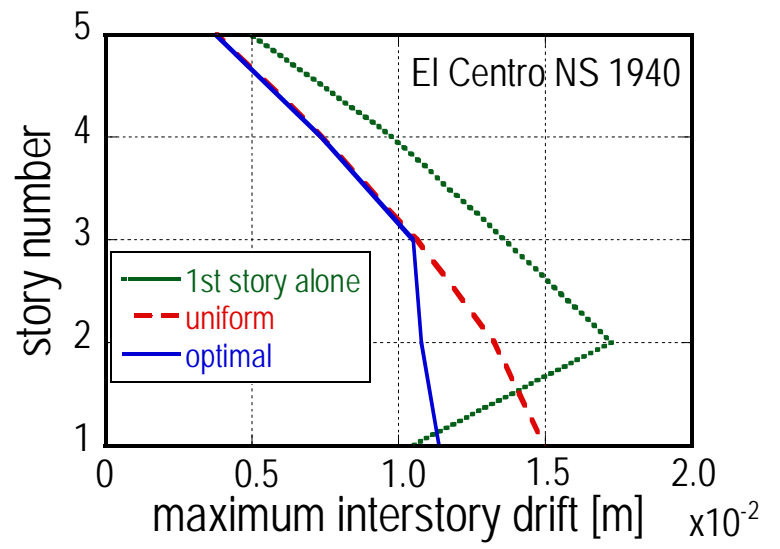

(c)

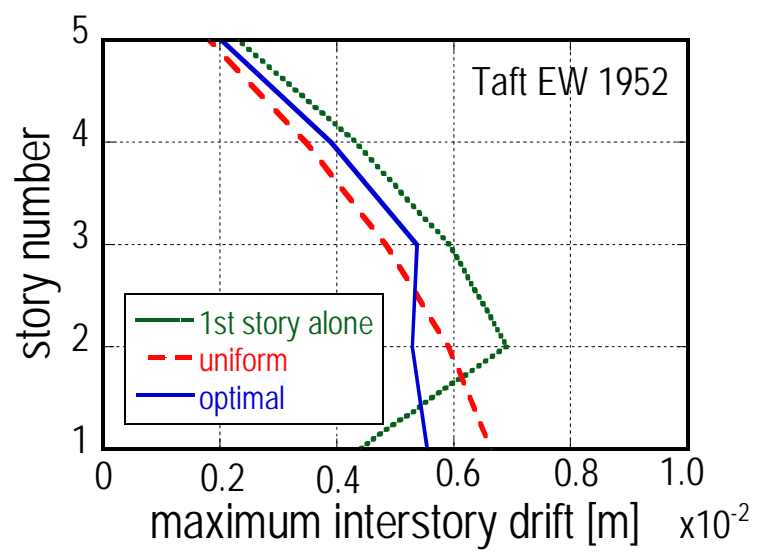

(e)

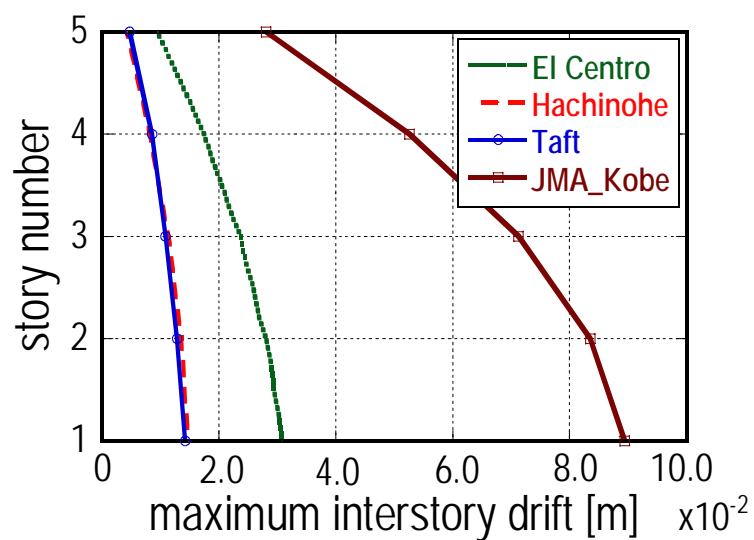

(b)

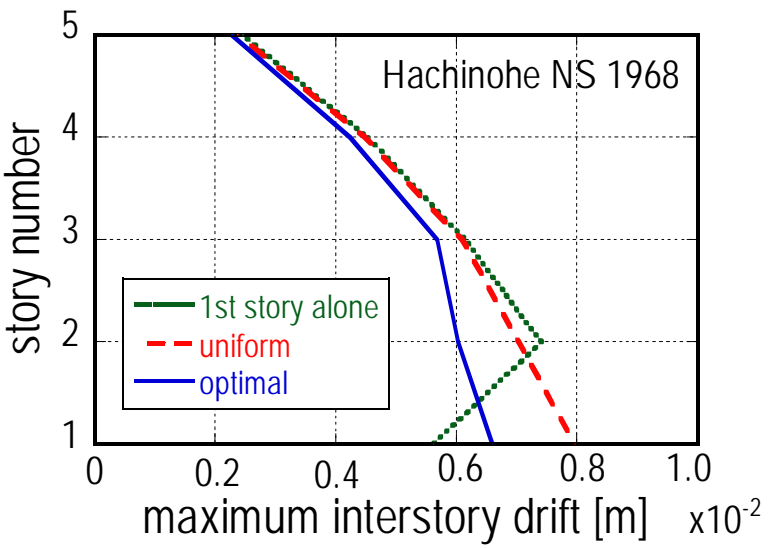

(d)

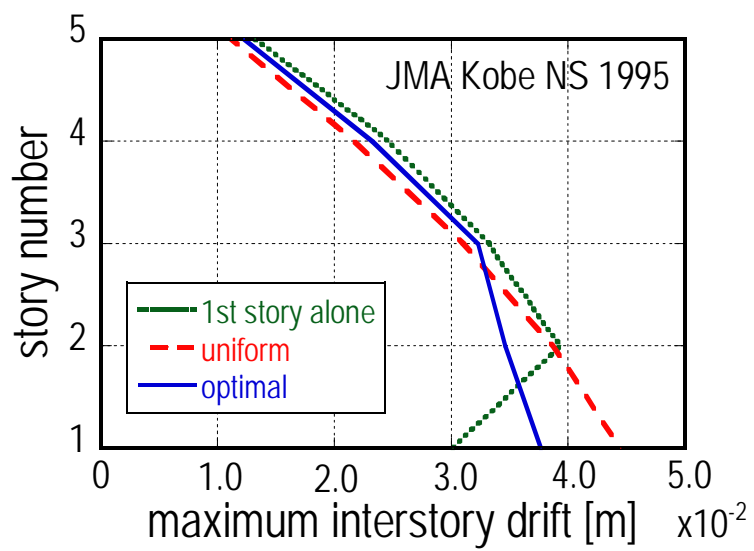

Fig.28 Maximum interstory drift of the models with various damper placements under recorded ground motions by time history response analysis

(a) El Centro NS 1940, (b) Hachinohe NS 1968, (c) Taft EW 1952, (d) JMA Kobe NS 1995,

(e) four recorded ground motions for a model without passive dampers 


\section{FUTURE DIRECTIONS}

Passive dampers possess various mechanical properties with fairly large degree of uncertainty. Dependency of their properties on frequency, temperature, loading-history and surrounding stiffness etc. is crucial for the development of reliable design methods. A unified treatment of these dependencies may be difficult and individual inclusion of these effects may be possible. For example, dependency on frequency may be overcome by the combination of springs and dashpots explained in Figs.5 and 6. For nonlinear dampers, an optimization method using numerical design sensitivities and reduced models (Suzuki et al. 2009, Fujita et al. 2010a) will be useful.

As the amount of dampers increases, the force in the damper-supporting member becomes larger (Fujita et al. 2010a). Introduction of excessive forces into the frame may be unfavorable in the structural rehabilitation aimed for weak frames. Devices or mechanisms to avoid the introduction of such excessive forces may be desired. Gradient-based approaches including the stress distributions in the original frame and the supporting members (Fujita et al. 2010a) can be used as promising ones.

Since a finite number of damper systems can be installed in actual buildings, discrete optimal design/placement may be another topic of great interest. Combination of gradient-based approaches and discrete design approaches can be one possibility with high efficiency and reliability.

\section{CONCLUSIONS}

The following conclusions have been obtained.

(1) Passive dampers are effective in reducing the building response under earthquake ground motions. The ratio of the stiffness of supporting members to the frame stiffness is very important in the effective use of passive dampers.

(2) The optimal damper placement depends strongly on the models of building structures.

(3) Gradient-based optimization methods are useful in the optimal damper placement and can be applied to various models of building structures.

(4) Passive dampers play a key role in the implementation of structural rehabilitation or retrofit which is essential for the realization and promotion of sustainable buildings. Structural health monitoring should be incorporated in the process of structural rehabilitation from the viewpoint of its reliability.

(5) The design earthquake ground motions change from time to time when a new class of ground motions (e.g. long-period ground motions due to surface waves) is observed or a new type of damage appears during severe earthquakes. The concept of critical excitation is useful in responding to this change together with the usage of passive dampers from the viewpoint of sustainable buildings and cities.

\section{ACKNOWLEDGEMENTS}

Part of the present work is supported by the Grant-in-Aid for Scientific Research of Japan Society for the Promotion of Science (No.20656086, 21360267). This support is greatly appreciated. 


\section{REFERENCES}

Aydin, E., Boduroglub, M.H., and Guney, D. (2007). "Optimal damper distribution for seismic rehabilitation of planar building structures”, Engineering Structures 29, 176-185.

Boller, C., Chang, F.-K. and Fujino, Y. (eds.) (2009). "Encyclopedia of Structural Health Monitoring, Wiley InterScience.

Casciati, F. (ed.) (2002). Proceedings of 3rd World Conference on Structural Control”. John Wiley \& Sons: Como.

Christopoulos, C., and Filiatrault, A. (2006). "Principle of Passive Supplemental Damping and Seismic Isolation”, IUSS Press, University of Pavia, Italy.

Cimellaro, G.P. (2007). "Simultaneous stiffness-damping optimization of structures with respect to acceleration, displacement and base shear”, Engineering Structures, 29, 2853-2870.

Connor, J.J., and Klink, B.S.A. (1996). "Introduction to Motion-based Design”, WIT Press.

de Silva, C.W. (ed.) (2007). “Vibration Damping, Control, and Design”, CRC Press.

Fujita, K., Moustafa, A. and Takewaki, I. (2010a). "Optimal placement of viscoelastic dampers and supporting members under variable critical excitations,” Earthquakes and Structures/ An Int. J., 1(1), 43-67.

Fujita, K., Yamamoto, K. and Takewaki, I. (2010b). "Optimal damper placement for minimum transfer function of interstorey drift in shear building," Proc. of the First Int. Conf. on Advances in Interaction and Multiscale Mechanics (AIMM'10), Jeju, Korea, 291-309.

Garcia, Diego Lopez (2001). "A simple method for the design of optimal damper configurations in MDOF structures”, Earthquake Spectra, 17(3), 387-398.

Gurgoze, M., and Muller, P.C. (1992). “Optimal positioning of dampers in multi-body systems”, J. Sound \& Vib. 158(3), 517-530.

Hahn, G.D., and Sathiavageeswaran, K.R. (1992). "Effects of added-damper distribution on the seismic response of buildings”, Computers \& Structures 43(5), 941-950.

Hanson, R.D., and Soong, T.T. (2001). "Seismic Design with Supplemental Energy Dissipation Devices", EERI, Oakland, CA.

Housner GW, Masri SF, Chassiakos AG. (eds). (1994). Proceedings of 1st World Conference on Structural Control. IASC: Los Angeles, CA.

Housner, G. et al. (1997). "Special issue, Structural control : past, present, and future”, J. Engng Mech ASCE 123(9), 897-971.

Johnson, E., and Smyth, A. (eds). (2006). Proceedings of 4th World Conference on Structural Control and Monitoring, (4WCSCM). IASC: San Diego, CA.

Kobori T, Inoue Y, Seto K, Iemura H and Nishitani A. (eds). (1998). Proceedings of 2nd World Conference on Structural Control. John Wiley \& Sons: Kyoto.

Lavan, O., and Dargush, GF. (2009). "Multi-objective evolutionary seismic design with passive energy dissipation systems,” J. Earthquake Engineering, 13(6), 758-790.

Lavan, O., and Levy, R. (2006). "Optimal design of supplemental viscous dampers for linear framed structures”, Earthquake Engineering \& Structural Dynamics, 35(3), 337-356.

Silvestri, S., and Trombetti, T. (2007). "Physical and numerical approaches for the optimal insertion of seismic viscous dampers in shear-type structures", J. Earthquake Engineering, 11(5): 787-828.

Silvestri, S., and Trombetti, T., and Ceccoli, C. (2003). "Inserting the mass proportional damping (MPD) system in a concrete shear-type structure”, Int. J. of Structural Engineering and Mechanics, 16(2), 177-193. 
Singh, M.P., and Moreschi, L.M. (2001). “Optimal seismic response control with dampers”, Earthquake Engineering \& Structural Dynamics, 30(4), 553-572.

Soong, T.T., and Dargush, G.F. (1997). "Passive Energy Dissipation Systems in Structural Engineering”, John Wiley \& Sons, Chichester.

Soong, T.T. (1998). "Structural control: Impact on structural research in general", Proc. of 2nd World Conf. on Structural Control, Vol.1, 5-14.

Srinivasan and McFarland (2000). "Smart Structures: Analysis and Design", Cambridge University Press.

Suzuki, C. Tsuji, M., Yoshitomi, S. and Takewaki, I. (2009). "Reduced load and structure models via inverse formulation for time-history wind response analysis of high-rise buildings,” $J$. Structural and Construction Engineering, AIJ, No.640, 1073-1080.

Takewaki, I. (1997). “Optimal damper placement for minimum transfer functions”, Earthquake Engineering \& Structural Dynamics, 26(11), 1113-1124.

Takewaki, I. (1999a). "Displacement-acceleration control via stiffness-damping collaboration," Earthquake Engineering \& Structural Dynamics, 28(12), 1567-1585.

Takewaki, I. (1999b). “Dynamic Structural Design: Inverse Problem Approach”, WIT Press.

Takewaki, I. (2000). “Optimal damper placement for planar building frames using transfer functions”, Structural and Multidisciplinary Optimization, 20(4), 280-287.

Takewaki, I. (2007). “Critical Excitation Methods in Earthquake Engineering," Elsevier, Amsterdam.

Takewaki, I. (2008a). “Critical excitation methods for important structures." EURODYN (Semi-plenary paper), July 7-9, 2008, Southampton, UK.

Takewaki, I. (2008b). "Robustness of base-isolated high-rise buildings under code-specified ground motions,” J. of The Structural Design of Tall and Special Buildings, 17(2), 257-271.

Takewaki, I. (2009). "Building Control with Passive Dampers: -Optimal Performance-based Design for Earthquakes-,” John Wiley \& Sons Ltd. (Asia), Singapore.

Takewaki, I. (2010). "Building control with passive dampers", Proc. of the First Int. Conf. on Advances in Interaction and Multiscale Mechanics (AIMM'10), Jeju, Korea, pp23-39.

Takewaki, I. and Ben-Haim, Y. (2005). "Info-gap robust design with load and model uncertainties.” J. Sound \& Vibration, 288(3), 551-570.

Takewaki, I. and Ben-Haim, Y. (2008). "Info-gap robust design of passively controlled structures with load and model uncertainties," Chapter 19 in "Structural Design Optimization Considering Uncertainties” (eds.) Yiannis Tsompanakis, Nikos D. Lagaros \& Manolis Papadrakakis, Taylor \& Francis, pp531-548.

Takewaki, I. and Fujita, K. (2009). "Earthquake input energy to tall and base-isolated buildings in time and frequency dual domains," J. of The Structural Design of Tall and Special Buildings, 18(6), 589-606.

Takewaki, I., and Nakamura, M. (2000). Stiffness-damping simultaneous identification using limited earthquake records, Earthquake Engineering and Structural Dynamics, 29(8), 1219-1238

Takewaki, I., and Nakamura, M. (2005). Stiffness-damping simultaneous identification under limited observation, Journal of Engineering Mechanics, ASCE, 131(10), 1027-1035

Takewaki, I., and Yoshitomi, S. (1998). "Effects of support stiffnesses on optimal damper placement for a planar building frame”, J. The Structural Design of Tall Buildings, 7(4), 323-336. 
Takewaki, I., Yoshitomi, S., Uetani, K., and Tsuji, M. (1999). “Non-monotonic optimal damper placement via steepest direction search”, Earthquake Engineering \& Structural Dynamics, 28(6), 655-670.

Trombetti T., and Silvestri, S. (2004). "Added viscous dampers in shear-type structures: The effectiveness of mass proportional damping”, J. Earthquake Engineering, 8(2), 275-313.

Tsuji, M., and Nakamura, T. (1996). "Optimum viscous dampers for stiffness design of shear buildings”, J. Structural Design of Tall Buildings 5, 217-234.

Uetani, K., Tsuji, M., and Takewaki, I. (2003). "Application of optimum design method to practical building frames with viscous dampers and hysteretic dampers," Engineering Structures, 25(5), 579-592.

Yamamoto, K., Fujita, K. and Takewaki, I. (2010). “ $H^{\infty}$ optimization in damper placement for interstory-drift control of structures," Proc. of the First Int. Conf. on Advances in Interaction and Multiscale Mechanics (AIMM'10), Jeju, Korea, 321-329.

Zhang, R.H., and Soong, T.T. (1992). "Seismic design of viscoelastic dampers for structural applications”, J. Struct. Eng., ASCE, 118(5), 1375-1392. 